\title{
The Trials of Psychedelic Therapy: LSD Psychotherapy in America, By Matthew Oram, Johns Hopkins University Press. 2018. 288 pp. £33.30 (hb). ISBN 9781421426204 - CORRIGENDUM
}

Ben Sessa

https://doi.org/10.1192/bjp.2019.95, Published online by Cambridge University Press, 10 July 2019

An error was made in the title of the aforementioned review (Sessa, 2019) when it was first published. The name of the author of The Trials of Psychedelic Therapy: LSD Psychotherapy in America is Matthew Oram, not Matthew Dram. The article has been corrected and an explanatory footnote added.
Ben Sessa

\section{Reference}

Sessa B. The Trials of Psychedelic Therapy: LSD Psychotherapy in America, By Matthew Oram, Johns Hopkins University Press. 2018. 288 pp. f33.30 (hb). ISBN 9781421426204. Br J Psychiatry, 2019; 215: 508-509.

\section{The role of prenatal stress as a pathway to personality disorder: Iongitudinal birth cohort study - CORRIGENDUM}

Ross Brannigan, Antti Tanskanen, Matti O. Huttunen, Mary Cannon, Finbarr P. Leacy and Mary C. Clarke

https://doi.org/10.1192/bjp.2019.190, Published by Cambridge University Press, 06 September 2019

Keywords: Epidemiology; personality disorders; prenatal stress; prospective study; psychiatry; corrigendum

When this article was originally published, there were several mistakes in the abstract and tables.

In the Results section of the abstract, the first odds ratio mentioned was given as $3.28,95 \% \mathrm{CI} 1.75-6.15, \mathrm{P}<0.0001$. This should have been $2.76,95 \%$ CI $1.59-4.80, \mathrm{P}=0.000$.

The third odds ratio mentioned was given as odds ratio 7.02 , 95\% CI 2.08-23.66, $\mathrm{P}=0.002$. This should have been $7.06,95 \%$ CI 2.10-23.81, $\mathrm{P}=0.002$.

In Table 1, the figures in the $N(\%)$ column under the heading "Maternal psychopathology" were reversed. It should have been as follows:

Yes: $224(6.2)$

No: $3402(93.8)$
Finally, in Table 3, the figures in the second row of the "Anxiety diagnosis" column, under "Moderate stress", were originally published as $3.59(0.89-1.13)$. This should have been 3.59 (1.47-8.78).

This article has now been fully updated and this corrigendum published.

Ross Brannigan; Antti Tanskanen; Matti O. Huttunen; Mary Cannon; Finbarr P. Leacy; Mary C. Clarke

\section{Reference}

Brannigan R, Tanskanen A, Huttunen MO, Cannon M, Leacy FP and Clarke MC. The role of prenatal stress as a pathway to personality disorder: Iongitudinal birth cohort study. Br J Psychiatry 2020; 216: 85-89. 